\section{Empfindlichkeit, maximale analytische und praktische analytische}

C. Vidal ${ }^{1}$ und W.-R. Külpmann ${ }^{2}$

${ }^{1}$ Landeskriminalamt Niedersachsen, Dezernat 53 „Chemie“, Hannover, Deutschland

${ }^{2}$ Hannover, Deutschland

Englischer Begriff maximal analytical sensitivity; practical analytical sensitivity

Definition Maß für die Empfindlichkeit einer qualitativen Untersuchung.

Beschreibung Zur Bestimmung der maximalen analytischen Empfindlichkeit werden Aliquote zahlreicher Proben (z. B. 30 Urinproben von 30 verschiedenen Probanden) mit unterschiedlichen Mengen des Analyten aufgestockt, s. folgende Abbildung:

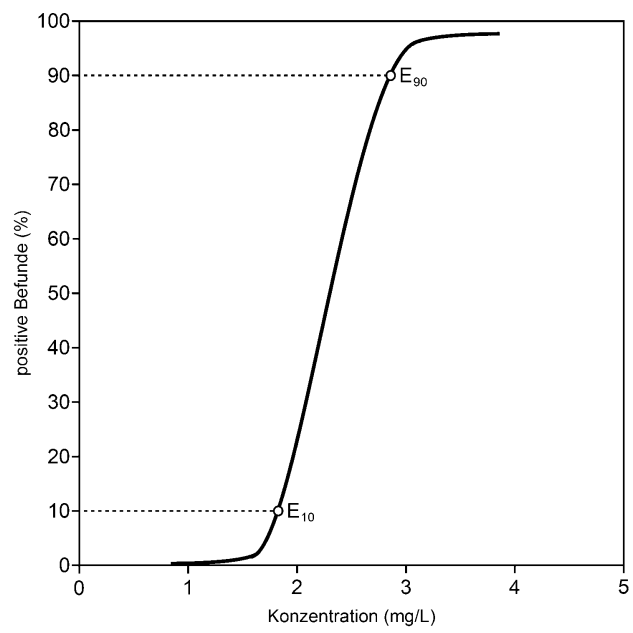

Die Konzentration, bei der $10 \%$ der Aliquote (in diesem Beispiel: 3) einen positiven Befund ergeben, entspricht der maximalen analytischen Empfindlichkeit $\left(\mathrm{E}_{10}\right)$. Die Konzentration, bei der $90 \%$ der Aliquote (in diesem Beispiel: 27) einen positiven Befund liefern, wird als praktische analytische Empfindlichkeit bezeichnet $\left(\mathrm{E}_{90}\right)$.

\section{Literatur}

Geldmacher-von Mallinckrodt M, Hallbach J, Külpmann WR (1995) Qualitätskontrolle qualitativer Untersuchungen. In: Gibitz HJ, Schütz H (Hrsg) Einfache toxikologische Laboratoriumsuntersuchungen bei akuten Vergiftungen. VCH-Verlag, Weinheim, S 83-99 